\title{
Quality of life impact of mental health conditions in England: results from the adult psychiatric morbidity surveys
}

\author{
Jennifer Roberts ${ }^{1}$, Pamela Lenton ${ }^{1}$, Anju D Keetharuth ${ }^{2^{*}}$ and John Brazier $^{2}$
}

\begin{abstract}
Background: The main objective is to present health state utility estimates for a broad range of mental health conditions including anxiety, depression, long-term depression, obsessive compulsive disorder, phobia, panic disorder, psychosis, alcohol and drug dependency that can be used in economic models.

Methods: This study uses pooled data from the Adult Psychiatric Morbidity Surveys carried out in 2000 and 2007 of a representative sample of the general population in England. Health state utility values measured by the SF-6D and EQ-5D indices are the dependent variables. Independent variables include background characteristics, mental health and physical health conditions. Regression models were estimated using OLS for the SF-6D and tobit for EQ-5D. Further regressions were carried out to consider the impact of mental health and physical health morbidities and the impact of severity of conditions on utility values.
\end{abstract}

Results: Mental health conditions tend to have a larger impact on health state utility values than physical health conditions. The mental health conditions associated with the highest decrements in utility are: depression, mixed anxiety and depressive disorders and long-term depression. Interaction terms used to model the effect of co-morbidities are generally found to be positive implying that simply adding the utility decrements for two mental health conditions overestimates the burden of the disease.

Conclusions: This paper presents reliable and representative community based mean SF-6D and EQ-5D estimates with standard errors for health state utility values across a broad range of mental health conditions that can be used in cost effectiveness modelling.

Keywords: EQ-5D, SF-6D, Health-related quality of life, Health state utility values, Mental health, Co-morbidities, Depression, Anxiety

\section{Background}

While the prevalence of mental health conditions is increasing in the UK, there is a dearth of country specific data on the impact of mental health conditions on health-related quality of life (HRQoL). There are a number of European studies that investigate HRQoL decrements as a result of mental health conditions but none of these includes the UK [1-3]. The focus of many surveys has been epidemiological in nature concentrating on prevalence of mental health conditions. Health state utility values (HSUVs) take the form of an index

\footnotetext{
* Correspondence: d.keetharuth@sheffield.ac.uk

${ }^{2}$ School of Health and Related Research, University of Sheffield, Sheffield, UK Full list of author information is available at the end of the article
}

constructed from an outcome measure normally anchored from zero to one to represent death and full health respectively. They are normally used by decisionmakers to evaluate and compare cost-effectiveness of various treatments. HSUVs are particularly scarce for more complex conditions like psychosis, phobia and panic disorder [4] and disutility associated with different levels of severity.

Decision makers such as the National Institute for Health and Care Excellence (NICE) in the UK recommend that the results of economic evaluations in healthcare are presented in terms of quality adjusted life years (QALYs) which are a composite measure of health related quality of life and life expectancy. The most

\section{Biomed Central}


commonly used measures for putting the 'Q' into the QALY are generic preference-based measures of health, such as the EQ-5D [5] and SF-6D [6].This paper seeks to address the lack of available HSUVs associated with mental health conditions by providing estimates that can be used in economic evaluation from a representative community based sample.

Another important feature of mental health conditions is the common existence of co-morbidities, arising from other mental health conditions as well as physical ones. Understanding the impact of one condition on HSUVs cannot be done in isolation, but only after controlling for other health conditions. Previous studies of mental health conditions have largely failed to do this. There are several studies in the literature that highlight the lack of consensus on how best to calculate HSUVs $[7,8]$. While attempts have been made to calculate HSUVs for comorbid physical conditions [9], for example by adding or multiplying the effects of separate conditions, there is still overall very little empirical research on comorbidities for those with mental health conditions.

\section{Aims of the study}

This paper has three objectives: (i) to estimate the impact of mental health disorders on quality of life in England (ii) to compare and contrast the impact of physical health and mental health co-morbidities on quality of life (iii) to assess the impact of severity of depression, anxiety, phobia and panic disorders on quality of life.

Specifically we estimate the decrement associated with various mental health disorders using the SF-6D and EQ-5D indices from a representative sample of the UK general population and controlling for a wide range of background variables.

\section{Methods \\ Data}

We used health-related quality of life data and information on health status collected in the Adult Psychiatric Morbidity Survey (APMS) carried out in 2000 and 2007 $[10,11]$. This is a rigorously conducted general population survey aiming to provide information on the prevalence of psychiatric conditions among people living in Great Britain, as well as their associated social disabilities and use of services. Each APMS recruited about 8,000 working age adults in private households. APMS is unique in the UK for having data on a broad range of conditions including common mental health disorders like depression, anxiety and obsessive compulsive disorder, psychotic conditions, personality disorders and alcohol and drug dependence. They also contain general health measures including the SF-12 health index, a measure from which the SF-6D preference based utility index can be obtained [12]. There is also information on socio-demographic data, education and employment, income and debt, accommodation and stressful life events. While the 2000 survey covered England, Wales and Scotland, APMS 2007 only interviewed people in England so our analysis uses data for England only.

In both years APMS interviews are conducted in two stages. First, a computer assisted personal interview in the respondents own home covering neurotic symptoms and disorders using the Clinical Interview Schedule Revised (CIS-R) and screening items on personality disorder and psychosis. CIS-R is a structured interview that has been standardised so that it can be administered by social survey interviewers. It enquires about 14 common neurotic symptoms allowing categorisation according to ICD-10 criteria. CIS- $\mathrm{R}$ also measures the severity of the condition and is widely used $[13,14]$. A second stage sample was chosen comprising respondents who satisfied screening criteria for psychotic and personality disorder. The second stage interviews were conducted by trained psychologists using Schedules for Clinical Assessment in Neuropsychiatry (SCAN) and Structured Clinical Interview (SCID-II). In 2000 (2007) there were 8580 (7461) initial interviews, a response rate of 54 (57)\%. At the second stage there were 638 (630) interviews and a response rate of $73(74) \%$. Our analysis sample comprises 5688 individuals in 2000 and 5388 individuals in 2007. Data for 2000 and 2007 are pooled.

\section{Measuring HSUVs}

Two generic preference-based measures were derived from the SF-12 data: SF-6D and the EQ-5D. The SF-6D health utility index is derived from individual responses to the SF-12, a generic health measure based on items taken from the SF-36 health survey, a standardised questionnaire used to assess patient health [15]. Brazier and Roberts [9] developed a preference based index for the SF-12 using an algorithm estimated from standard gamble valuations of a sample of SF-6D states obtained from members of the UK general population [6]. The index takes values that range from zero (equivalent to dead) to one (full health).

The EQ-5D questionnaire consists of 5 simple questions on mobility, self-care, usual activities, pain and discomfort, anxiety and depression. As raw data was not collected from respondents using the EQ-5D questionnaire, EQ-5D scores have been generated through mapping from SF12 items using a response approach mapping [16]. It is deemed important to present the utilities using the EQ-5D, since the former is the method preferred by NICE in the reference case [17]. In the response mapping approach, multinomial logistic regression is used to estimate the probability that a respondent 
will select a particular level of response to questions in the EQ-5D, using individual question responses from the SF-12 as predictors. EQ-5D responses are predicted using Monte Carlo simulation methods and UK tariffs are then applied to the raw scores to generate the EQ5D index [5].

\section{Measuring severity of conditions}

It is often useful to know the severity of the condition, as quality of life decrements and health care costs are usually much higher for greater levels of morbidity. Each condition is diagnosed via a set of four questions from the CIS-R. For example in the case of anxiety these are: (i) felt generally anxious/nervous/tense for 4 days or more in the past seven days; (ii) in past seven days anxiety/nervousness/tension has been very unpleasant; (iii) in the past seven days have felt any of the following symptoms when anxious/nervous/tense (Racing heart, sweating or shaking hands, feeling dizzy, difficulty getting one's breath, dry mouth, butterflies in stomach, nausea or wanting to vomit); (iv) felt anxious/nervous tense for more than three hours in total on any one of the past seven days. Each question scores one if that symptom was present, giving a total anxiety score ranging from zero for no symptoms to four. This score can be used as a measure of severity of the condition. A similar approach was taken with depression, panic and phobia.

\section{Analysis}

The basic model to be estimated is:

$$
U_{i}=f\left(M_{i}, P_{i}, X_{i}, \varepsilon_{i}\right)
$$

Where $U_{i}$ is health utility for respondent $i$; $M$ is mental health, $P$ is physical health and $X$ is a set of background characteristics, $\varepsilon_{\mathrm{i}}$ is a random error term.

Two separate sets of analyses are carried out with SF6D and EQ-5D as dependent variables. The initial modelling was undertaken using Ordinary Least Squares (OLS) but this can be criticised. OLS estimates are biased and inconsistent, because both the SF-6D and EQ-5D distributions are skewed and in addition the EQ$5 \mathrm{D}$ distribution is truncated with many observations at the upper value of one [18]. To overcome these problems, OLS models for SF-6D are estimated with robust error variance as Breusch-Pagan/Cook-Weisberg tests results suggest heteroskedastic errors, and for the EQ$5 \mathrm{D}$, tobit models are used to deal with the truncated nature of the data.

Mental health $(M)$ is measured by a set of dichotomous variables to represent the presence of specific disorders. Diagnosis of specific disorders were assigned by the Office of National Statistics using answers to various sections of the CIS-R and applying algorithms based on the ICD-10 diagnostic criteria; these disorders are: generalised anxiety disorder (GAD), mixed anxiety depressive disorder (MADD), panic disorder, obsessive compulsive disorder (OCD), phobia, and depression. Psychosis and personality disorder are assigned via the Stage 1 screening questions, alcohol dependence is defined according to the Severity of Alcohol Dependence questionnaire (SAD-Q) and drug dependence defined according to questions used in the US Epidemiologic Catchment Area survey. A variable was generated to represent people who selfreport that they have long-term depression lasting for a period of 2 years or over [19]. More detail on definitions for each disorder can be found in the APMS technical reports $[10,11]$.

Physical health $(P)$ is measured by a set of dichotomous variables denoting the presence of self-reported long-standing health conditions: muscular-skeletal, respiratory, digestive, heart and circulatory, urinary, skin, ear, eye, neoplasm, blood disorder, and infection. The set of background variables $(X)$ include age, marital status, presence of children aged 16 or under in the household, employment status, ethnicity, education and income. Dummy variables for regions and year are also included. A full list of variables and definitions can be obtained from the corresponding author.

Although co-morbidities are an important issue for cost-effectiveness modelling, there is no consensus about the best method to estimate HSUVs for co-morbidities [7]. To allow a flexible approach we have explored all first order interactions between mental health conditions and physical health conditions by estimating models (2) and (3) below:

$$
\begin{aligned}
& U_{i}=f\left(M_{i}, P_{i}, X_{i} I M_{i}, \varepsilon_{i}\right) \\
& U_{i}=f\left(M_{i}, P_{i}, X_{i} I P_{i}, \varepsilon_{i}\right)
\end{aligned}
$$

Where $I M$ is a set of dichotomous variables representing first order interactions between the seven mental health conditions described above and $I P$ is a set of dichotomous variables representing first order interactions between the seven mental health conditions and the seven physical health conditions described above. It was not possible to investigate co-morbidities for personality disorder, psychosis and panic due to the small number of observations. In addition some physical conditions could not be considered due to small sample sizes, including ear complaints, neoplasm, blood disorder and infectious disorder. Data from the APMS was downloaded from the UK Data Archive [20] and STATA 11 was used for the analysis.

\section{Results}

Table 1 reports descriptive statistics for the entire sample of 11080 cases. The distribution of the SF-6D health 
Table 1 Descriptive statistics for entire sample

\begin{tabular}{|c|c|c|}
\hline & $\mathrm{N}$ & $\%$ \\
\hline Total sample & 11080 & \\
\hline Male & 4893 & 44.2 \\
\hline Single & 2405 & 21.7 \\
\hline Married & 6796 & 61.3 \\
\hline widow/divorced/separated & 1879 & 17.0 \\
\hline Children under 16 & 3786 & 34.2 \\
\hline Education- Degree & 2151 & 19.4 \\
\hline Education- HND/Teach/Nursing & 854 & 7.7 \\
\hline Education - A level & 1680 & 15.2 \\
\hline Education - GCSE/O level & 3048 & 27.5 \\
\hline Education - lower level & 760 & 6.9 \\
\hline Education - none & 2448 & 22.1 \\
\hline Gross personal income <£5200 p.a. & 2218 & 20.0 \\
\hline Gross personal income 5200-10399 p.a. & 2118 & 19.1 \\
\hline Gross personal income 10400 -15559 р.а. & 1781 & 16.1 \\
\hline Gross personal income 15560 m-20799 p.a. & 1278 & 11.5 \\
\hline Gross personal income 20800 -33799 p.a. & 1885 & 17.0 \\
\hline Gross personal income >33800 p.a. & 1074 & 9.7 \\
\hline Non white & 1084 & 9.8 \\
\hline \multirow[t]{2}{*}{ Working } & 7794 & 70.3 \\
\hline & Mean & Standard deviation \\
\hline Age in years & 42.7 & 12.8 \\
\hline SF-6D index & 0.791 & 0.139 \\
\hline EQ-5D index & 0.808 & 0.206 \\
\hline
\end{tabular}

utility index is negatively skewed with a concentration at the higher end of the scale (Additional file 1: Figure S1a). However there is no obvious ceiling or floor effect and only a small proportion of observations take the value of one (less than $5 \%$ ). While the mean scores for SF-6D (0.791) and EQ-5D (0.808) are very similar, the distributions are very different. The EQ-5D distribution has a ceiling effect with $33 \%$ of observations at full health. SF-6D and EQ-5D scores range between 0.35 and 1 and between -0.38 and 1 respectively (Additional file 1: Figure S1b).

Table 2 shows the descriptive statistics on physical and mental health conditions with mean utility scores. Around $82 \%$ of people in this dataset have no mental health disorder, similar to the prevalence rate reported in the APMS reports $[10,11]$. The most common problem is Mixed Anxiety Depressive disorder (MADD) found in around 10\% of respondents, and this is followed by alcohol dependency, which is here defined as any level of dependency detected by the SADQ, ranging from mild to severe. The SF-6D (EQ-5D) scores for those with no physical health problem and no mental
Table 2 Descriptive statistics: utility scores for people with physical and mental health conditions

\begin{tabular}{|c|c|c|c|c|c|c|}
\hline Physical health & $n$ & $\%$ & $\begin{array}{l}S F-6 D \\
\text { mean }\end{array}$ & $\begin{array}{r}S F-6 D \\
s d\end{array}$ & $\begin{array}{l}E Q-5 D \\
\text { mean }\end{array}$ & $\begin{array}{r}E Q-5 D \\
s d\end{array}$ \\
\hline $\begin{array}{l}\text { No physical health } \\
\text { problems }\end{array}$ & 5879 & 53.1 & 0.829 & 0.114 & 0.851 & 0.165 \\
\hline $\begin{array}{l}\text { Muscular/skeletal } \\
\text { complaint }\end{array}$ & 2471 & 22.3 & 0.709 & 0.160 & 0.705 & 0.258 \\
\hline Respiratory complaint & 969 & 8.7 & 0.726 & 0.159 & 0.740 & 0.254 \\
\hline Digestive complaint & 606 & 5.5 & 0.706 & 0.163 & 0.710 & 0.261 \\
\hline Heart/circulatory complaint & 1232 & 11.1 & 0.732 & 0.162 & 0.741 & 0.251 \\
\hline Urinary related complaint & 588 & 5.3 & 0.689 & 0.159 & 0.696 & 0.276 \\
\hline Skin complaint & 726 & 6.6 & 0.747 & 0.147 & 0.763 & 0.225 \\
\hline Ear complaint & 434 & 3.9 & 0.737 & 0.154 & 0.752 & 0.247 \\
\hline Eye complaint & 819 & 7.4 & 0.756 & 0.152 & 0.771 & 0.235 \\
\hline Neoplasm & 117 & 1.1 & 0.689 & 0.160 & 0.710 & 0.261 \\
\hline Blood disorder & 214 & 1.9 & 0.725 & 0.165 & 0.722 & 0.275 \\
\hline Infectious disorder & 52 & 0.5 & 0.681 & 0.142 & 0.702 & 0.240 \\
\hline \multicolumn{7}{|l|}{ Mental health } \\
\hline $\begin{array}{l}\text { No mental health } \\
\text { problems* }\end{array}$ & 8263 & 74.6 & 0.827 & 0.114 & 0.842 & 0.170 \\
\hline $\begin{array}{l}\text { Generalised anxiety } \\
\text { disorder }\end{array}$ & 613 & 5.5 & 0.626 & 0.141 & 0.643 & 0.288 \\
\hline $\begin{array}{l}\text { Mixed anxiety depressive } \\
\text { disorder }\end{array}$ & 1098 & 9.9 & 0.657 & 0.131 & 0.681 & 0.258 \\
\hline Panic disorder & 121 & 1.1 & 45 & 134 & 0.664 & 0.274 \\
\hline $\begin{array}{l}\text { Obsessive compulsive } \\
\text { disorder }\end{array}$ & 162 & 1.5 & 0.576 & 0.113 & 0.593 & 0.294 \\
\hline Phobia & 267 & 2.4 & 0.573 & 0.114 & 0.577 & 0.297 \\
\hline Depression & 367 & 3.3 & 0.551 & 0.105 & 0.537 & 0.311 \\
\hline Long-term depression & 187 & 1.7 & 0.532 & 0.104 & 0.513 & 0.324 \\
\hline Psychosis & 81 & 0.7 & 0.623 & 0.138 & 0.665 & 0.281 \\
\hline Personality disorder & 31 & 0.3 & 0.648 & 0.153 & 0.706 & 0.274 \\
\hline Alcohol dependency (any) & 781 & 7.0 & 0.761 & 0.144 & 0.790 & 0.222 \\
\hline Drug dependency & 379 & 3.4 & 0.732 & 0.144 & 0.774 & 0.216 \\
\hline \multicolumn{7}{|l|}{ Neurotic symptoms score } \\
\hline cisr score_1 $(0-5)$ & 7146 & 64.5 & 0.848 & 0.100 & 0.861 & 0.152 \\
\hline cisr score_2 (6 - 11) & 1954 & 17.6 & 0.744 & 0.126 & 0.774 & 0.205 \\
\hline cisr score_3 (12 -17) & 957 & 8.6 & 0.679 & 0.125 & 0.712 & 0.237 \\
\hline cisr score_4 (18 -23) & 489 & 4.4 & 0.617 & 0.125 & 0.636 & 0.273 \\
\hline cisr score_5 (24 -29) & 282 & 2.5 & 0.572 & 0.112 & 0.576 & 0.291 \\
\hline cisr score_6 (30 -35) & 161 & 1.5 & 0.542 & 0.098 & 0.536 & 0.306 \\
\hline cisr score_7 (36+) & 91 & 0.8 & 0.518 & 0.099 & 0.464 & 0.338 \\
\hline
\end{tabular}

*No mental health problem category includes a score of 11 or below on the cis-r scale.

problem are $0.829(0.851)$ and $0.827(0.842)$ respectively. All the scores for the EQ-5D are marginally higher than the SF-6D. Long-term depression and depression sufferers have the lowest SF-6D (EQ-5D) scores of 0.532 
(0.513) and $0.551(0.537)$ respectively. According to the neurotic symptoms score, those with more severe symptoms have monotonically lower utility scores as measured by both SF-6D and EQ-5D.

The results from the OLS and tobit regressions for SF-6D and EQ-5D respectively are shown in Table 3. Marginal effects have been calculated at the means of the explanatory variables for tobit regressions. The highest decrements in HSUVs are observed for depression, MADD, long-term depression and GAD for both SF-6D and EQ-5D. The HSUV decrements in SF-6D (EQ-5D) scores are as follow: depression -0.137 (-0.159); MADD -0.136 (-0.127); long-term depression -0.100 (-0.118); GAD -0.086 (-0.070); phobia -0.083 $(-0.081)$; panic -0.077 (-0.076); OCD $-0.057 \quad(-0.034)$ and; drug dependency $-0.027(-0.011)$. The three mental health conditions that do not have a statistically significant effect on health utility are psychosis, personality disorder and alcohol dependence. The coefficients for psychosis and personality disorder may be insignificant due to the small numbers of people (81 and 31 respectively) suffering from these conditions. All of the physical health conditions, except eye complaints, are statistically significant at $1 \%$ level of significance. In the models for both SF-6D and EQ-5D, socio-demographic characteristics were controlled for. They are not reported in this paper but are available by request from authors.

For the OLS regression for SF-6D, the adjusted $\mathrm{R}^{2}$ is 0.41 but the Ramsey Regression Equation Specification Error Test (RESET) [21] and Pregibon [22] link test statistics suggest that the model suffers from omitted variables and misspecification problems respectively. It is worth noting that these tests also revealed misspecification problems with both tobit [23] and Postestimation Generalized Linear Models (PGLM) models [24,25] which were also explored for the SF-6D (not reported here). The marginal effects of physical and mental health conditions on the SF-6D index are very similar regardless of the estimation procedure and functional form chosen, a finding similar to that of Jones [26] who compared a number of different models for modelling health care cost data. In the case of EQ-5D as the dependent variable, the link test suggests that the model is correctly specified making tobit regression a better model than OLS in this case.

\section{Co-morbid Health Conditions}

Table 4 reports the results for the models exploring interactions between mental health conditions. Only the coefficients on the main mental health conditions and the significant (at $\mathrm{p}=0.05$ ) interactions are reported. The coefficients on the mental health conditions are different compared to Table 3 but remain statistically
Table 3 Health decrements in SF-6D and EQ-5D scores

\begin{tabular}{|c|c|c|c|c|c|c|}
\hline & \multicolumn{3}{|c|}{$\begin{array}{c}\mathrm{SF}-6 \mathrm{D} \\
\text { (OLS regression) }\end{array}$} & \multicolumn{3}{|c|}{$\begin{array}{c}\text { EQ-5D } \\
\text { (Tobit regression) }\end{array}$} \\
\hline & Coefficient & & $\mathrm{SE}$ & Coefficient & & SE \\
\hline male & 0.011 & $* * *$ & 0.002 & 0.015 & $* * *$ & 0.004 \\
\hline age & -0.005 & $* * *$ & 0.001 & -0.002 & ** & 0.001 \\
\hline \multicolumn{7}{|c|}{ Mental health conditions } \\
\hline $\begin{array}{l}\text { Generalised anxiety } \\
\text { disorder }\end{array}$ & -0.086 & $* * *$ & 0.006 & -0.070 & $* * *$ & 0.009 \\
\hline $\begin{array}{l}\text { Mixed anxiety } \\
\text { depressive disorder }\end{array}$ & -0.136 & $* * *$ & 0.004 & -0.127 & $* * *$ & 0.007 \\
\hline Panic disorder & -0.077 & $* * *$ & 0.012 & -0.076 & $* * *$ & 0.019 \\
\hline $\begin{array}{l}\text { Obsessive compulsive } \\
\text { disorder }\end{array}$ & -0.057 & $* * *$ & 0.011 & -0.034 & $* *$ & 0.016 \\
\hline Phobia & -0.083 & $* * *$ & 0.008 & -0.081 & $* * *$ & 0.015 \\
\hline Depression & -0.137 & $* * *$ & 0.007 & -0.159 & $* * *$ & 0.014 \\
\hline Long-term depression & -0.100 & $* * *$ & 0.01 & -0.118 & $* * *$ & 0.019 \\
\hline Psychosis & -0.001 & & 0.011 & 0.017 & & 0.02 \\
\hline Personality disorder & -0.010 & & 0.024 & 0.013 & & 0.032 \\
\hline $\begin{array}{l}\text { Alcohol dependency } \\
\text { (any) }\end{array}$ & -0.002 & & 0.004 & 0.006 & & 0.007 \\
\hline Drug dependency & -0.027 & $* * *$ & 0.006 & -0.011 & & 0.01 \\
\hline \multicolumn{7}{|c|}{ Physical health conditions } \\
\hline $\begin{array}{l}\text { Muscular/skeletal } \\
\text { complaint }\end{array}$ & -0.071 & $* * *$ & 0.003 & -0.093 & $* * *$ & 0.005 \\
\hline Respiratory complaint & -0.029 & $* * *$ & 0.004 & -0.025 & $* * *$ & 0.007 \\
\hline Digestive complaint & -0.030 & $* * *$ & 0.005 & -0.032 & $* * *$ & 0.008 \\
\hline $\begin{array}{l}\text { Heart/circulatory } \\
\text { complaint }\end{array}$ & -0.028 & $* * *$ & 0.004 & -0.025 & $* * *$ & 0.006 \\
\hline $\begin{array}{l}\text { Urinary related } \\
\text { complaint }\end{array}$ & -0.040 & $* * *$ & 0.005 & -0.037 & $* * *$ & 0.009 \\
\hline Skin complaint & -0.016 & $* * *$ & 0.004 & -0.019 & $* *$ & 0.008 \\
\hline Ear complaint & -0.028 & $* * *$ & 0.006 & -0.016 & & 0.01 \\
\hline Eye complaint & -0.006 & & 0.004 & -0.004 & & 0.007 \\
\hline Neoplasm & -0.054 & $* * *$ & 0.012 & -0.046 & ** & 0.019 \\
\hline Blood disorder & -0.034 & $* * *$ & 0.009 & -0.039 & $* * *$ & 0.015 \\
\hline Infectious disorder & -0.050 & $* * *$ & 0.018 & -0.037 & & 0.028 \\
\hline Constant & 0.881 & $* * *$ & 0.013 & & & \\
\hline Observations & 10,289 & & & & & \\
\hline $\begin{array}{l}\text { R-squared/Pseudo R- } \\
\text { squared }\end{array}$ & 0.413 & & & 0.252 & & \\
\hline $\begin{array}{l}\text { Reset test (omitted } \\
\text { variables) }\end{array}$ & 79.07 & $* * *$ & & & & \\
\hline $\begin{array}{l}\text { Pregibon link test } \\
\text { (model specification) }\end{array}$ & 0.348 & $* * *$ & 0.084 & 0.108 & & \\
\hline Chi-square & & & & 2153 & $* * *$ & \\
\hline
\end{tabular}

Note: Socio-demographics variables including education, income level, ethnicity, working status and regions have been controlled for in the model but are not reported here. ${ }^{* * *} p<0.01,{ }^{* *} p<0.05,{ }^{*} p<0.1$. 
Table 4 Utility values for mental health co-morbidities: SF6 and EQ-5D scores

\begin{tabular}{|c|c|c|c|c|c|c|c|}
\hline & \multirow[b]{2}{*}{$\mathbf{N}$} & \multicolumn{3}{|c|}{ SF 6D OLS models } & \multicolumn{3}{|c|}{ EQ-5D tobit models } \\
\hline & & Coefficient & & $\overline{\text { se }}$ & Coefficient & & se \\
\hline $\begin{array}{l}\text { Generalised } \\
\text { anxiety disorder }\end{array}$ & & -0.094 & $* * *$ & 0.006 & -0.081 & $* * *$ & 0.010 \\
\hline OCD & & -0.099 & $* * *$ & 0.012 & -0.091 & $* * *$ & 0.023 \\
\hline GAD X OCD & 70 & 0.103 & $* * *$ & 0.019 & 0.097 & $* * *$ & 0.019 \\
\hline $\begin{array}{l}\text { Generalised } \\
\text { anxiety disorder }\end{array}$ & & -0.101 & $* * *$ & 0.006 & -0.081 & $* * *$ & 0.010 \\
\hline Phobia & & -0.133 & $* * *$ & 0.010 & -0.115 & $* * *$ & 0.019 \\
\hline GAD X Phobia & 124 & 0.121 & $* * *$ & 0.015 & 0.063 & $* * *$ & 0.019 \\
\hline $\begin{array}{l}\text { Generalised } \\
\text { anxiety disorder }\end{array}$ & & -0.107 & $* * *$ & 0.006 & -0.086 & $* * *$ & 0.011 \\
\hline Depression & & -0.182 & $* * *$ & 0.007 & -0.195 & $* * *$ & 0.018 \\
\hline $\begin{array}{l}\text { GAD X } \\
\text { Depression }\end{array}$ & 162 & 0.122 & $* * *$ & 0.013 & 0.068 & $* * *$ & 0.016 \\
\hline $\begin{array}{l}\text { Generalised } \\
\text { anxiety disorder }\end{array}$ & & -0.094 & $* * *$ & 0.006 & -0.078 & $* * *$ & 0.000 \\
\hline $\begin{array}{l}\text { Alcohol } \\
\text { Dependency }\end{array}$ & & -0.008 & * & 0.051 & -0.0001 & & 0.008 \\
\hline $\begin{array}{l}\text { GAD X Alcohol } \\
\text { Dependency }\end{array}$ & 90 & 0.057 & $* * *$ & 0.015 & 0.050 & $* * *$ & 0.018 \\
\hline $\begin{array}{l}\text { Generalised } \\
\text { anxiety disorder }\end{array}$ & & -0.090 & $* * *$ & 0.006 & -0.076 & $* * *$ & 0.010 \\
\hline $\begin{array}{l}\text { Drug } \\
\text { Dependency }\end{array}$ & & -0.033 & $* * *$ & 0.006 & -0.019 & $*$ & 0.011 \\
\hline $\begin{array}{l}\text { GAD X Drug } \\
\text { Dependency }\end{array}$ & 48 & 0.057 & $* * *$ & 0.021 & 0.064 & $* * *$ & 0.023 \\
\hline MADD & & -0.138 & $* * *$ & 0.004 & -0.132 & $* * *$ & 0.008 \\
\hline $\begin{array}{l}\text { Alcohol } \\
\text { Dependency }\end{array}$ & & -0.006 & & 0.004 & -0.001 & & 0.008 \\
\hline $\begin{array}{l}\text { MADD X Alcohol } \\
\text { dependency }\end{array}$ & 111 & 0.024 & * & 0.012 & 0.044 & $* * *$ & 0.017 \\
\hline OCD & & -0.096 & $* * *$ & 0.012 & -0.072 & $* * *$ & 0.021 \\
\hline Phobia & & -0.105 & $* * *$ & 0.009 & -0.102 & $* * *$ & 0.016 \\
\hline OCD X Phobia & 56 & 0.133 & $* * *$ & 0.020 & 0.091 & $* * *$ & 0.021 \\
\hline OCD & & -0.110 & $* * *$ & 0.013 & -0.096 & $* * *$ & 0.024 \\
\hline Depression & & -0.155 & $* * *$ & 0.007 & -0.181 & $* * *$ & 0.015 \\
\hline $\begin{array}{l}\text { OCD X } \\
\text { Depression }\end{array}$ & 78 & 0.127 & $* * *$ & 0.019 & 0.101 & $* * *$ & 0.018 \\
\hline Phobia & & -0.127 & $* * *$ & 0.010 & -0.090 & $* * *$ & 0.018 \\
\hline Depression & & -0.165 & $* * *$ & 0.008 & -0.165 & $* * *$ & 0.016 \\
\hline $\begin{array}{l}\text { Phobia X } \\
\text { Depression }\end{array}$ & 111 & 0.126 & $* * *$ & 0.016 & 0.023 & & 0.023 \\
\hline Depression & & -0.144 & $* * *$ & 0.007 & -0.151 & $* * *$ & 0.015 \\
\hline $\begin{array}{l}\text { Alcohol } \\
\text { Dependency }\end{array}$ & & -0.005 & & 0.004 & 0.009 & & 0.007 \\
\hline $\begin{array}{l}\text { Depression X } \\
\text { Alcohol } \\
\text { Dependency }\end{array}$ & 73 & 0.040 & $* *$ & 0.017 & -0.040 & & 0.028 \\
\hline
\end{tabular}

***p $<0.01,{ }^{* *} p<0.05,{ }^{*} p<0.1$. significant. The first point to note is that the coefficients on all of the interaction terms are positive implying that having both conditions results in a health utility decrement that is less than the sum of the individual coefficients. For example, having GAD and depression, the decrement to the SF-6D index is -0.107 $0.182+0.122=-0.167$; this is smaller than that suggested by the additive model of -0.289 . In this case it is also highlighted that the interaction term more than offsets the main effects of GAD. Similarly using EQ$5 \mathrm{D}$, the decrement associated with GAD and depression is -0.213 . Despite the insignificant main effects for alcohol dependence, there are significant positive interactions with GAD, MADD (EQ-5D only) and depression.

Table 5 reports the results to explore interactions with physical conditions; only for models where the coefficients on the main health conditions and the interactions are significant (at $p=0.05$ ). The coefficients on the mental and physical health conditions are similar to those in Table 3 and are statistically significant. Of the interactions reported, the majority are positive, meaning that the presence of both disorders reduces health utility by a smaller amount than that suggested by the additive model. The only interaction terms that are negative are MADD and respiratory complaints, and MADD and muscular skeletal complications with the latter interaction being insignificant.

\section{Severity of mental health condition}

We have explored the severity of four conditions: depression $(n=367)$, anxiety $(n=613)$, phobia $(n=267)$ and panic $(\mathrm{n}=121)$. We estimate model (1) and in the vector $M$, the dichotomous variable for the presence of anxiety (depression) is replaced with a set of four dummy variables indicating the score, compared to a baseline of zero. The results are shown in Table 6; the effect on other coefficients is negligible so only the estimated coefficients on the new set of dummy variables are reported. The results for depression are as expected, the utility decrement increases with the severity of the condition.

For anxiety, while there is a gradient overall from level 1 to 4 , the estimated coefficient for levels 3 and 4 have very similar decrements. In this case, the levels have been aggregated to represent only two severity levels with the more severe level showing a higher SF-6D (EQ-5D) decrement of $-0.070(-0.068)$ compared with the lower severe level of $-0.047(-0.032)$.

The severity levels for phobia and panic have also been aggregated to distinguish between two severity levels. In the case of phobia, higher decrements are observed in both SF-6D and EQ-5D scores for the more severe levels. It is noted that the EQ-5D scores are not 
Table 5 Utility values for mental health and physical health co-morbidities: SF6 and EQ-5D scores

\begin{tabular}{|c|c|c|c|c|c|c|c|}
\hline & & & moc & & EQ- & it $\mathrm{mc}$ & \\
\hline & $\mathbf{N}$ & Coefficient & & se & Coefficient & & se \\
\hline Generalised anxiety disorder & & -0.095 & $* * *$ & 0.006 & -0.077 & $* * *$ & 0.012 \\
\hline Muscular/skeletal complaint & & -0.073 & $* * *$ & 0.003 & -0.094 & $* * *$ & 0.005 \\
\hline GAD X muscular/skeletal & 233 & 0.025 & $* *$ & 0.011 & 0.015 & & 0.015 \\
\hline Generalised anxiety disorder & & -0.090 & $* * *$ & 0.006 & -0.075 & $* * *$ & 0.010 \\
\hline Digestive complaint & & -0.034 & $* * *$ & 0.006 & -0.036 & $* * *$ & 0.009 \\
\hline GAD $X$ digestive complaint & 74 & 0.034 & * & 0.017 & 0.03 & & 0.021 \\
\hline Generalised anxiety disorder & & -0.091 & $* * *$ & 0.006 & -0.071 & $* * *$ & 0.010 \\
\hline Urinary complaint & & -0.044 & $* * *$ & 0.006 & -0.038 & $* * *$ & 0.009 \\
\hline GAD X Urinary complaint & 75 & 0.039 & $* * *$ & 0.018 & 0.008 & & 0.023 \\
\hline Generalised anxiety disorder & & -0.091 & & 0.006 & -0.079 & $* * *$ & 0.010 \\
\hline Eye complaint & & -0.009 & $* *$ & 0.004 & -0.009 & & 0.007 \\
\hline GAD X eye complaint & 71 & 0.039 & $* *$ & 0.018 & 0.06 & $* * *$ & 0.019 \\
\hline MADD & & -0.133 & $* * *$ & 0.004 & -0.125 & $* * *$ & 0.008 \\
\hline Respiratory complaint & & -0.025 & $* * *$ & 0.004 & -0.023 & $* * *$ & 0.007 \\
\hline MADD X respiratory complaint & 150 & -0.025 & $* *$ & 0.010 & -0.013 & & 0.017 \\
\hline MADD & & -0.139 & $* * *$ & 0.004 & -0.126 & $* * *$ & 0.007 \\
\hline Urinary complaint & & -0.045 & $* * *$ & 0.006 & -0.035 & $* * *$ & 0.010 \\
\hline MADD X Urinary complaint & 113 & 0.028 & $* *$ & 0.013 & -0.009 & & 0.020 \\
\hline MADD & & -0.139 & $* * *$ & 0.004 & -0.132 & $* * *$ & 0.007 \\
\hline Skin complaint & & -0.020 & $* * *$ & 0.005 & -0.027 & $* * *$ & 0.008 \\
\hline MADD X skin complaint & 97 & 0.031 & $* *$ & 0.013 & 0.049 & $* * *$ & 0.018 \\
\hline MADD & & -0.136 & $* * *$ & 0.004 & -0.121 & $* * *$ & 0.009 \\
\hline Muscular/skeletal complaint & & -0.071 & $* * *$ & 0.003 & -0.090 & $* * *$ & 0.005 \\
\hline MADD X muscular/skeletal & 369 & -0.001 & & 0.008 & -0.016 & & 0.013 \\
\hline Depression & & -0.154 & $* * *$ & 0.008 & -0.188 & $* * *$ & 0.017 \\
\hline Muscular/skeletal complaint & & -0.073 & $* * *$ & 0.003 & -0.096 & $* * *$ & 0.005 \\
\hline Depression X muscular/ skeletal & 127 & 0.053 & $* * *$ & 0.013 & 0.062 & $* * *$ & 0.016 \\
\hline Depression & & -0.147 & $* * *$ & 0.007 & -0.166 & $* * *$ & 0.015 \\
\hline Respiratory complaint & & -0.032 & $* * *$ & 0.004 & -0.027 & $* * *$ & 0.007 \\
\hline Depression $\mathrm{X}$ respiratory complaint & 63 & 0.060 & $* * *$ & 0.016 & 0.032 & & 0.023 \\
\hline Depression & & -0.143 & $* * *$ & 0.007 & -0.164 & $* * *$ & 0.015 \\
\hline Urinary complaint & & -0.043 & $* * *$ & 0.006 & -0.040 & $* * *$ & 0.009 \\
\hline Depression X Urinary complaint & 57 & 0.039 & * & 0.006 & 0.030 & & 0.025 \\
\hline Phobia & & -0.097 & $* * *$ & 0.009 & -0.086 & $* * *$ & 0.018 \\
\hline Muscular/skeletal complaint & & -0.072 & $* * *$ & 0.003 & -0.093 & $* * *$ & 0.005 \\
\hline Phobia X muscular/skeletal & 100 & 0.038 & ** & 0.016 & 0.012 & & 0.022 \\
\hline Alcohol dependency & & -0.007 & & 0.004 & 0.0001 & & 0.008 \\
\hline Muscular/skeletal complaint & & -0.072 & $* * *$ & 0.003 & -0.095 & $* * *$ & 0.005 \\
\hline Alcohol dependency X muscular/skeletal & 176 & 0.019 & * & 0.011 & 0.024 & & 0.015 \\
\hline
\end{tabular}

${ }^{* * *} p<0.01,{ }^{* *} p<0.05,{ }^{*} p<0.1$.

significant. However, for panic disorder both SF-6D and EQ-5D show a lower decrement for the more severe level and only the SF6D value is significant. This is possibly mainly due the fact that there are only 57 and 64 individuals in the less severe and more severe categories respectively. 
Table 6 Impact of severity of Anxiety, Depression, Phobia and Panic on SF-6D and EQ-5D scores

Depression ( $n=367$ with depression present)

\begin{tabular}{lrrrr}
\hline & Score $\mathbf{1} \mathbf{n}=\mathbf{1 0 4 7}$ & Score $\mathbf{2} \mathbf{n = 7 5}$ & Score $\mathbf{3} \mathbf{n}=\mathbf{2 1 9}$ & Score $\mathbf{4} \mathbf{n}=\mathbf{7 3}$ \\
\hline SF6 - coefficient & $-0.062^{* * *}$ & $-0.084^{* * *}$ & $-0.127^{* * *}$ & $-0.149^{* * *}$ \\
SF6 - standard error & 0.004 & 0.005 & 0.006 & 0.010 \\
EQ-5D - coefficient & $-0.052^{* * *}$ & $-0.069^{* * *}$ & $-0.120^{* * *}$ & $-0.177^{* * *}$ \\
EQ-5D- standard error & 0.007 & 0.009 & 0.011 & 0.021
\end{tabular}

Anxiety ( $n=613$ with anxiety present)

Score $1 \mathrm{n}=\mathbf{2 7 7}$

$-0.047^{* * *}$

0.003

$-0.032^{* * *}$

0.006

Score $1 \mathrm{n}=139$

$-0.017^{* * *}$

0.004

$-0.010$

0.007

Score $\mathbf{1} \mathrm{n}=\mathbf{5 7}$

$-0.040^{* * *}$

0.011

$-0.015$

0.019
Score $\mathbf{2} \mathbf{n}=\mathbf{3 3 6}$

$-0.070 * * *$

0.006

$-0.068^{* * *}$

0.012

Score $2 \mathrm{n}=138$

$-0.039 * * *$

0.005

$-0.012$

0.010

Score $2 \mathrm{n}=64$

$-0.037$

0.01

$-0.024$

0.016

EQ-5D- standard error

${ }^{* * *} p<0.01, * * p<0.05,{ }^{*} p<0.1$. "**" refers to $p<0.1$ or $10 \%$ significance level.

\section{Discussion}

Our estimates from over 10,000 responses to the APMS 2000 and 2007 show that all but three of the mental health conditions considered here have a statistically significant and relatively large adverse effect on health utility measured by both SF-6D and EQ-5D indices. These effects are larger than for self-reported physical health conditions. Another study also found that HRQoL decrements from mental health conditions are higher than those reported by suffers of chronic physical conditions [1]. Depression, MADD and GAD are the mental health conditions that impact most on health. The three mental health conditions that are not statistically significant are alcohol dependency, personality disorder and psychosis. In considering co-morbidities, we have used interaction terms and in most cases they are significant confirming the fact that we cannot simply add HSUVs decrement of co-morbid health conditions. The impact on HSUVs is generally less than the addition of the separate health conditions. When considering interactions between mental and physical health conditions, the majority are positive, however in one case the interaction is negative and significant suggesting that the presence of both conditions reduces health utility by a larger amount that the additive model would suggest. Brief exploration of the effects of the severity of anxiety and depression on the health utility index, suggest that for depression the results are as expected, the utility decrement increasing with the severity of the condition. However, for anxiety, panic and phobia, only two severity levels were considered.

Utility decrements have been measured using both SF6D and EQ-5D predicted using a published mapping function. Both measures on the whole depict a similar picture. In general, for most physical and mental health conditions, the decrements shown by SF-6D and EQ-5D are similar and this finding is supported by a study comparing SF-6D and EQ-5D across seven patient groups with physical health conditions [27]. A multi-centre randomised control trial in Netherlands [28] found that EQ-5D utilities led to significant higher health gains even though EQ-5D mean scores were lower than SF-6D scores at baseline. A study on patients with schizophrenia revealed similar EQ-5D and SF-6D mean scores at baseline but higher EQ-5D mean scores higher at follow-up [29]. 
In model [3], the utility decrements for eye complaints are statistically insignificant. This finding is line with a recent review where it was found that SF-6D and EQ-5D are inadequate measures for such conditions [30]. Similarly, the insignificant coefficient for psychosis is in line with the finding that generic measures are not suitable for use in schizophrenia, a psychotic disorder [31]. An additional reason why personality disorder and psychosis are not statistically significant could be due to relatively small numbers, as less than $1 \%$ of the sample has these conditions. For alcohol dependency we explored whether the insignificant result was due to our relatively broad definition of any dependency, by testing the effects of moderate and severe dependence on alcohol (as defined by the SADQ) alone, but these were not statistically significant either. Another study found that alcohol dependence was insignificant but similar to this paper, it was not possible to understand how and why this was the case [1].

The effects of co-morbidities are investigated through interaction terms. For the majority of mental health comorbidities, the interaction terms are positive and often offset the decrement caused by a single condition. While it is understandable that this may be the case, clinically it is difficult to explain. It may be that patients get better at managing their conditions having been exposed to another mental health condition. In the presence of a mental health condition and a physical health condition, some of the results are very surprising. First, several of the interaction terms as measured by EQ-5D score are statistically insignificant even though the both main effects are statistically significant. These include GAD and muscular/skeletal complaints, GAD and digestive complaint, GAD and urinary complaints, MADD and urinary complaints, MADD and skin complaints, depression and respiratory complaints, phobia and muscular/skeletal complaints. This is not the case when the dependent variable is SF-6D. It may be due to the artefact of the mapping approach. In some cases, the main effects are not statistically significant but the interaction terms are. Examples include alcohol dependency and digestive complaints, where alcohol dependency is insignificant but the interaction term is significant. In this case, it is not clear whether it is acceptable to use the HSUVs thus generated. A possible explanation for the latter result is the fact that alcohol may be used to alleviate the symptoms of GAD and MADD.

\section{Limitations}

Overall the models we have estimated have good explanatory power but the RESET test does suggest misspecification problems. We have explored both tobit and generalised linear models for the SF-6D but these were still wrongly specified. The EQ-5D index also suffers from ceiling effects and therefore more sophisticated models may be used to address that. Despite the weaknesses of OLS regressions in the case of SF-6D, it was decided to present the results as they are easy to interpret and in the absence of better estimates, those generated in this paper can be readily used in decision-analytic models.

It is worth stressing here that the data we have used to estimate these models is not based on clinical diagnosis of mental health conditions, but instead on wellestablished instruments administered by trained interviewers. Furthermore, while data on the mental health conditions are reliable, the data on physical conditions are self-reported and are therefore less reliable since there was no confirmation of the conditions. Finally, the data is limited to those living in private households, though this accounts for the vast majority of people with these conditions.

There may also be a concern as to whether a generic measure of health like the SF-12 adequately assesses the impact of all mental disorders - particularly personality disorders and psychosis. The other limitation is that the EQ-5D estimates are based on a mapping function that been shown to have a tendency to underestimate values at the upper end of the scale and overestimate values at the lower end. Other mapping functions have not overcome this limitation and it may result in an underestimate of the impact of different conditions [32].

\section{Conclusions}

Despite these limitations, this study has a number of interesting findings. First, the estimates provided are based on a representative sample of the UK population. Generally HSUV are generated from trial data and there are always questions as to whether they can be generalised and used outside the trial setting. Therefore the decrements associated with the various mental health conditions and co-morbidities in this paper can be readily used in decision-analytic models in assessing costeffectiveness of health technologies. Second the APMS is regarded as the most reliable available data in the UK in the area of mental health.

There are several implications of this paper. First, background characteristics need to be controlled for when estimating HSUVs. This is very important but often not accounted in single condition studies. As a result the HSUV decrement associated with a particular health condition is possibly higher which, in turn has implications in cost-effectiveness analysis. Second, the paper has also been able to generate estimates for HSUVs associated with long-term depression. Third, the paper shows that simply adding HSUVs for co-morbid health conditions is not appropriate. Fourth, it provides decrements that can be used to reflect severity of the following conditions: depression, anxiety, panic and 
phobia. These are useful parameters that can be used in decision analytic models where conditions of patients may be shown to progress.

\section{Additional file}

Additional file 1: Definition and variables used in the analysis. Figure 1a: Distribution of SF-6D index. Figure 1b: Distribution of EQ-5D index.

\section{Abbreviations}

APMS: Adult Psychiatric Morbidity Survey; CIS-R: Clinical Interview Schedule Revised; GAD: Generalised Anxiety Disorder; HSUV: Health State Utility Values; MADD: Mixed Anxiety Depressive Disorder; NICE: National Institute for Health and Care Excellence; OCD: Obsessive Compulsive Disorder; OLS: Ordinary Least Squares; PGLM: Postestimation Generalized Linear Models; QALY: Quality Adjusted Life Year; HRQoL: Health-Related Quality of Life; RESET: Ramsey Regression Equation Specification Error Test; SAD-Q: Severity of Alcohol Dependence Questionnaire; SCAN: Schedules for Clinical Assessment in Neuropsychiatry; SCID - II: Structured Clinical Interview.

\section{Competing interests}

The authors declare that they have no competing interests.

\section{Authors' contributions}

$P L, J R$ and JB designed the study. JR and PL prepared the dataset and carried out initial analysis for the report submitted to the funder. ADK carried out further statistical analyses and wrote the paper. All authors have read and approved the final manuscript.

\section{Acknowledgements}

The study was funded by the National Institute of Health and Research (NIHR) methods opportunity funding scheme grant. The corresponding author undertook some extra analysis on the data for this paper during a placement fellowship funded by the Economic and Social Research Council (ESRC), NIHR, Medical Research Council (MRC) and Collaboration for Leadership in Applied Health Research and Care for South Yorkshire (CLAHRC-SY).

\section{Source of financial support}

NIHR Methods Opportunity Funding Scheme Grant.

\section{Author details}

'Department of Economics, University of Sheffield, Sheffield, UK. ${ }^{2}$ School of Health and Related Research, University of Sheffield, Sheffield, UK.

Received: 15 July 2013 Accepted: 8 January 2014

Published: 14 January 2014

\section{References}

1. Alonso J, Angermeyer MC, Bernert S, et al: Disability and quality of life impact of mental health disorders in Europe: results from the European Study of the Epidemiology of Mental Health Disorders (ESEMeD) project. Acta Psychiat Scand 2004, 109(Suppl 420):38-46.

2. Saarni SI, Suvisaari J, Sintonen $\mathrm{H}$, et al: Impact of psychiatric disorders on health-related quality of life: general population survey. The Brit J Psychiat 2007, 190(4):326-332.

3. Paykel ES, Brugha T, Fryers T: Size and burden of depressive disorders in Europe. Eur Neurol 2005, 15(4):411-423.

4. Brazier J: Measuring and valuing mental health for use in economic evaluation. J Health Serv Res Po 2008, 13(Suppl 3):70-75.

5. Dolan P: Modeling valuations for EuroQol health states. Med Care 1997, 35(11):1095-1108.

6. Brazier J, Roberts J, Deverill M: The estimation of a preference-based measure of health from the SF-36. J Health Econ 2002, 21(2):271-292.

7. Ara $R$, Wailoo $A$ : Using health state utility values in models exploring the cost-effectiveness of health technologies. Value Health 2012, 15(6):971-974.

8. Peasgood T, Ward SE, Brazier J: Health-state utility values in breast cancer. Expert review of pharmacoeconomics \& outcomes research 2010, 10(5):553-566.
9. Ara R, Brazier J: Estimating Health State Utility Values for Comorbid Health Conditions Using SF-6D Data.; 2010. HEDS discussion paper series 2010, White Rose Research Online [http://eprints.whiterose.ac.uk/11049/]

10. McManus S, Meltzer H, Brugha TS, Bebbington PE, Jenkins R: Adult Psychiatric Morbidity in England, 2007: Results of a Household Survey. England: The Information Centre; 2009.

11. Singleton N, Lee A, Meltzer H: Psychiatric Morbidity Among Adults Living in Private Households. London: Office of National Statistics Technical Report; 2000.

12. Brazier JE, Roberts J: The estimation of a preference-based measure of health from the SF-12. Med care 2004, 42(9):851-859.

13. Lewis G, Pelosi AJ, Araya R, Dunn G: Measuring psychiatric disorder in the community: a standardized assessment for use by lay interviewers. Psychol Med 1992, 22(02):465-486.

14. NatCen: Adult Psychiatry Morbidity Survey 2007: User guide. Leicester: NatCen; 2007.

15. Ware JE, Snow KK, Kosinski M, Gandek B: SF-36 Health Survey Manual and Interpretation guide. Boston: MA: New England Medical Center. The Health Institute; 1993.

16. Gray AM, Rivero-Arias O, Clarke PM: Estimating the association between SF-12 responses and EQ-5D utility values by response mapping. Med Decis Making 2006, 26(1):18-29.

17. National Institute for Health and Clinical Excellence: Guide to the Methods of Technology Appraisal. London: NICE; 2008.

18. Greene WH: Econometric Analysis. Upper Saddle River, NJ: Prentice Hall; 2000.

19. Keller MB, McCullough JP, Klein DN, Arnow B, Dunner DL, Gelenberg AJ, et al: A comparison of nefazodone, the cognitive behavioral-analysis system of psychotherapy, and their combination for the treatment of chronic depression. New Engl J Med 2000, 342(20):1462-1470.

20. In National Centre for Social Research and University of Leicester, Adult Psychiatric Morbidity Survey, 2007 [computer file]. 3rd edition. Edited by. Colchester, Essex: UK Data Archive [distributor]; January 2011. SN: 6379, http://dx.doi.org/10.5255/UKDA-SN-6379-1 doi:10.5255/UKDA-SN-63791\#_blank.

21. Ramsey JB: Tests for specification errors in classical linear least-squares regression analysis. J R Stat Soc 1969, 31(2):350-371.

22. Pregibon D: Goodness of link tests for generalized linear models. App/ Statis 1980, 29(1):15-24.

23. Tobin J: Estimation of relationships for limited dependent variables. Econometrica 1958, 29(1):24-36.

24. Basu A: Extended generalized linear models: Simultaneous estimation of flexible link and variance functions. The Stata J 2005, 5(4):501-516.

25. Basu A, Rathouz PJ: Estimating marginal and incremental effects on health outcomes using flexible link and variance function models. Biostatistics 2005, 6(1):93-109.

26. Jones AM: Models for Health Care. Centre for Health Economics, University of York; 2010.

27. Brazier J, Roberts J, Tsuchiya A, Busschbach J: A comparison of the EQ5-D and SF-6D across seven patient groups. Health Econ 2004, 13(9):873-884.

28. Lamers LM, Bouwmans CAM, Van Straten A, Donker MCH, Hakkaart L: Comparison of EQ-5D and SF-6D utilities in mental health patients. Health Econ 2006, 15(11):1229-1236.

29. McCrone P, Patel A, Knapp M, Schene A, Koeter, Ammadeo F, et al: A comparison of SF-6D and EQ-5D utility scores in a study of patients with schizophrenia. J Ment Health Policy 2009, 12.1:27-31.

30. Tosh J, Brazier J, Evans P, Longworth L: A review of generic preferencebased measures of health-related quality of life in visual disorders. Value Health 2012, 15(1):118-127.

31. Papaioannou D, Brazier J, Parry G: How valid and responsive are generic health status measures, such as EQ-5D and SF-36, in schizophrenia? A systematic review. Value Health 2011, 14(6):907-920.

32. Brazier JE, Yang Y, Tsuchiya A, Rowen DL: A review of studies mapping (or cross walking) non-preference based measures of health to generic preference-based measures. Eur J Health Econ 2010, 11(2):215-225.

doi:10.1186/1477-7525-12-6

Cite this article as: Roberts et al.: Quality of life impact of mental health conditions in England: results from the adult psychiatric morbidity surveys. Health and Quality of Life Outcomes 2014 12:6. 